\title{
EL DECAIMIENTO DEL CONTROL CONSTITUCIONAL DIFUSO EN SEDE ADMINISTRATIVA EN UN ESTADO CONSTITUCIONAL DE DERECHO
}

\author{
THE DECAY OF DIFFUSE CONSTITUTIONAL CONTROL BY \\ ADMINISTRATIVE COURTS IN A CONSTITUTIONAL STATE OF LAW
}

CONTROL CONSTITUCIONAL NISQA PISIASHAN KALLPAN CHAY SEDE ADMINISTRATIVAPI ANKIY ESTADO CONSTITUCIONAL DE DERECHO NISQAPI ${ }^{(1)}$

\author{
Alfredo Fernández Ttito ${ }^{(2)}$ \\ Universidad Nacional de San Antonio Abad del Cusco
}

\begin{abstract}
Resumen: Este ensayo analiza la jurisprudencia del Tribunal Constitucional del Perú acerca de la negación del control constitucional difuso por la administración pública (Sentencia del expediente 04293-2012-PA/TC /Caso Consorcio Requena). Dicha decisión cambia el precedente vinculante del Tribunal Constitucional (expediente 3741-2004-PA/TC) por el que todo juzgado u órgano colegiado de la administración pública tenía el deber de preferir la Constitución frente a una disposición infra constitucional. Conforme a una interpretación de la Constitución no solo el Poder Judicial ejerce función jurisdiccional, sino otros entes públicos que ejercen función administrativa, pues ostentan potestades para decidir conflictos intersubjetivos planteados por los administrados y tienen atribuciones para imponer sanciones y limitar derechos, con autoridad de cosa decidida.
\end{abstract}

Palabras Clave: Control constitucional, Estado Constitucional de Derecho, Supremacía Constitucional.

Abstract: This essay analyzes the jurisprudence of the Constitutional Court of Peru regarding the denial of diffuse constitutional control by the public administration

(1) Traducción: Alejandra C. Ninahuaman Quispe, Kilmer Ttito Quispe (Lengua Quechua / Cusco Qollao).

(2) Doctor. Profesor de la Escuela Profesional de Derecho de la Universidad Nacional de San Antonio Abad del Cusco, e-mail: fredoal40@hotmail.com 
(Judgment of the file 04293-2012-PA / TC / Consorcio Requena Case). This decision changes the binding precedent of the Constitutional Court (file 3741-2004-PA / TC) by which every court or collegiate body of the public administration had the duty to prefer the Constitution over an infra constitutional provision. According to an interpretation of the Constitution, not only does the Judicial Power exercise jurisdictional functions, but also other public entities that exercise administrative functions, as they have powers to decide intersubjective conflicts raised by the administrations and have powers to impose sanctions and limit rights, with the authority of matter determined.

Key words: Constitutional control, Constitutional State, Constitutional Supremacy.

Ñujñu: Kay qelqay qawarichin chay jurisprudencia del tribunal constitucional nisqata Perú suyunchismanta achhuyachin imaynata kay control constitucional mana reqsichinchu allinta chay admistracion publicaman (Sentencia del expediente 04293-2012-PA/TC /Caso Consorcio Requena). chay rimakuy hoq hinaman tukuchin chay precedente vinculante del tribunal constitucional nisqata (expediente 3741-2004-PA/TC) chayqa ima juzgadopis órgano colegiado de la administración públicapis ruwaranku constitucion politica hap'irispa. Chaynata constitución politicata yachayninkuman rimachinku, mana sapallantachu poder judicial kamachin jurisdiccionalmanta, ichaqa hoq entes públicos kamachin chay función administrativa nisqapi, paykuna atinku ima ruwaytapas conflicto kaqtin administradukunamanta, paykuna atinku sancionayta q'utuchiyta derechonkunatapas, aqnata paykunapis atinku kay ruwaykunata.

Kichana rimaykuna: Control constitucional, Estado Constitucional de Derecho, Supremacía Constitucional. 


\section{Introducción}

El presente artículo describe y explica los criterios adoptados por el Tribunal Constitucional, sobre la negación del control constitucional difuso en sede administrativa, dejando sin efecto un precedente anterior.

Covián Andrade señala: "El control de constitucionalidad es el conjunto de recursos jurídicos diseñados para verificar la correspondencia entre los actos emitidos por quienes decretan el poder y la Constitución, anulándolos cuando aquellos quebranten los principios constitucionales. (COVIÁN ANDRADE, 2013)"

El fundamento de este control constitucional es el mantenimiento del principio de Supremacía Constitucional. En ese sentido, seguidamente se analiza la problemática a partir de dos sentencias controversiales emitidas por el Tribunal Constitucional; la primera en el expediente 04293-2012-PA/TC, cuya decisión vulnera la protección de derechos fundamentales en sede administrativa y menoscaba el principio jurídico de supremacía constitucional; si se tiene en cuenta que, a partir del precedente vinculante establecido en la sentencia emitida en el expediente 3741-2004-PA/TC, los órganos colegiados de competencia nacional tenían facultades para inaplicar una ley cuando de su análisis e interpretación resultaba contraria a la Constitución; entonces se podía resguardar y garantizar plenamente los derechos fundamentales en sede administrativa. Tal situación, con la decisión del Tribunal Constitucional, se ha extinguido, pues a partir de dicha resolución la Administración Pública al ejercer potestad administrativa y resolver controversias administrativas, solo podrá aplicarse la ley, aun cuando dicha norma legal presente evidencia de inconstitucionalidad.

En ese sentido es relevante conocer de qué manera la negación del control constitucional difuso en sede administrativa desprotege los derechos fundamentales de los administrados y menoscaba el principio jurídico de supremacía constitucional.

Asimismo, se pretende identificar cuál es la implicancia constitucional de permitir a tribunales administrativos y órganos colegiados ejercer control constitucional difuso y establecer si la escasa aplicación del control constitucional difuso es sustento suficiente para prohibir dicho control en sede administrativa; además dilucidar si el control constitucional difuso es atribución exclusiva del poder judicial y de quienes ejercen función jurisdiccional.

Consideramos que la decisión del Tribunal Constitucional no permite garantizar de modo real y efectivo los derechos e intereses de los administrados, violentando el debido proceso, la legalidad y la tutela procesal; por ello con el presente ensayo se pretende efectuar un análisis constitucional, para posibilitar la restitución del control difuso en sede administrativa o su aplicación en el marco del Estado constitucional de derecho y la supremacía constitucional, máxime si se 
tiene en cuenta que la defensa de la persona humana y el respeto de su dignidad son el fin supremo de la sociedad y del Estado.

En ese sentido, se toma como referencia decisiones del Tribunal Constitucional, sobre control constitucional difuso en sede administrativa, doctrina nacional e internacional; sin perder de vista conceptos sobre Estado Constitucional de Derecho, separación de poderes, supremacía constitucional, jerarquía de normas jurídicas, interpretación sistemática y teleológica de la Constitución Política.

\section{El control constitucional difuso}

Se ha indicado que el control constitucional difuso es aquella institución jurídica constitucional por la cual los jueces $u$ otras instancias, al ejercer la función jurisdiccional y las competencias que corresponda en un caso concreto, podrán inaplicar una norma de rango legal que transgreda la Constitución.

El control constitucional difuso o Judicial Review, es el sistema que otorga facultades de control constitucional a los órganos jurisdiccionales u otras instancias del Estado, quienes tienen la misión de velar por la prevalencia de la Constitución. Entonces con el control difuso se delegan funciones para evaluar la constitucionalidad de una ley.

Esta inaplicación de la norma legal inconstitucional descansa en el principio de supremacía constitucional, el mismo que erige a la Constitución como norma fundamental y base de todo el ordenamiento jurídico.

Este sistema de control difuso es paralelo al control concentrado, teniendo existencia indistinta, dando lugar a un sistema de control constitucional dual. El sistema dual ha sido adoptado en numerosos países de América Latina, bajo la influencia europea, particularmente en Colombia, Guatemala, Bolivia, Perú y Ecuador.

Al respecto Higthon, señala "El método difuso llamado también esquema de revisión judicial o judicial review, por el cual se deja en manos de los jueces que integran el Poder Judicial la tarea de interpretar y aplicar la ley en el caso concreto, respetando en sus sentencias el principio de la supremacía constitucional. Este sistema denominado difuso confiere a todos los jueces la tarea de control. O sea que todos los jueces son jueces de legalidad y de constitucionalidad" (HIGTHON DE NOLASCO, 2003).

El maestro Brewer, indica que excepcionalmente, en algunos casos, como sucede en Panamá, el control de la constitucionalidad que ejerce la Corte Suprema de Justicia no sólo se refiere a las leyes y demás actos de rango legal, sino materialmente a todos los actos estatales, lo que lo hace único en el mundo (BREWER-CARIAS, 2005).

Por otro lado, en el Exp. 01680-2005-PA/TC en el segundo fundamento, al desarrollar la institución del control difuso, el propio Tribunal Constitucional 
expuso: "Este Tribunal tiene dicho que el control judicial de constitucionalidad de las leyes es una competencia reconocida a todos los órganos jurisdiccionales para declarar la inaplicabilidad constitucional de la ley, con efectos particulares, en todos aquellos casos en los que la ley aplicable para resolver una controversia resulta manifiestamente incompatible con la Constitución (control difuso)".

\section{El desarrollo del control constitucional difuso}

El artículo $10^{\circ}$ de la Constitución de 1856, establecía: “Es nula y sin efecto cualquier norma en cuanto se oponga a la Constitución".

El profesor español Francisco Fernández Segado, al referirse a este artículo, señala que éste nos muestra un esbozo de justicia constitucional; sin embargo, agrega que ésta permaneció en el puro plano teórico no sirviendo de base para la creación de un procedimiento de control, ni para la modificación del control político preexistente (FERNÁNDEZ SEGADO, 1994).

Por otro lado, García Belaunde, señala que con la consagración del Habeas Corpus en la Constitución de 1920, esta garantía constitucional se convirtió en uno de los cauces a través del que se ejercitaron algunas pautas del control difuso de constitucionalidad (GARCIA BELAUNDE, 1982).

En 1923, la comisión reformadora del Código Civil procedió a debatir la iniciativa del connotado jurista, político y diplomático peruano Alfredo Solf y Muro, quien propuso la inclusión en el Título Preliminar la cláusula siguiente: "Cuando haya incompatibilidad entre una disposición constitucional y una legal, se preferirá a la primera".

Tras un largo debate en la sesión de 28 de febrero de 1923, quedaba consagrada dicha cláusula, que después de trece años, en 1936, adquiriría la naturaleza normativa, dado que fue especificada en el artículo XII del Título Preliminar del Código Civil de 1936.

Domingo García Belaunde, al referirse a la recepción del control difuso en el Título Preliminar del Código Civil, refiere que los civilistas de aquel tiempo, entre ellos, el profesor José Barandiarán y el Constitucionalista José Pareja Paz Soldán dieron una buena recepción de esta normatividad; es así que éste último en sus comentarios a la Constitución Nacional expresó que "el principio de la no aplicación de las leyes inconstitucionales constituye un complemento indispensable del Poder Judicial (...) representa un avance en la vida institucional de la República, uno de los fenómenos a la tendencia a la racionalización del poder y una oportuna defensa de los principios y normas constitucionales". (GARCIA BELAUNDE, 1982, pág. 123)

Con el transcurso del tiempo se preparó un proyecto de Ley Orgánica del Poder Judicial que fue aprobado por el gobierno de facto de aquella época, dirigido por el general Ricardo Pío Pérez Godoy (1962-1963), con la Ley Nº 14506 se incorporó el siguiente texto: Artículo 8.- “Cuando los jueces y tribunales, al conocer 
de cualquier clase de juicios, encuentran que hay incompatibilidad entre una disposición constitucional y una legal, preferirán la primera".

a. "Si no fueran apeladas las sentencias de primera instancia en que se aplique este precepto, se elevarán en consulta a la Primera Sala de la Corte Suprema".

b. "Las sentencias de segunda instancia se elevarán en consulta a la Primera Sala de la Corte Suprema, sino se interpusiera recurso de nulidad".

Como es evidente, es el primer párrafo del artículo $8^{\circ}$ de la Ley 14506 el que incorpora por primera vez el control difuso de constitucionalidad de las leyes, siendo las demás normas las reglas de procedimiento que tendrán que seguir los magistrados para aplicar el control difuso constitucional.

Posteriormente el control difuso de constitucionalidad y el control abstracto fueron recogidos por la Constitución de 1979.

Conforme indica García Belaunde, lo importante de la Constitución de 1979 es que por primera vez se formaliza un sistema de jurisdicción constitucional al más alto nivel, aprovechando la experiencia peruana que venía desde atrás, pero al mismo tiempo introduciendo algunos aspectos del constitucionalismo europeo contemporáneo como el control abstracto de constitucionalidad o control concentrado de constitucionalidad, iniciándose, lo que García Belaunde denomina "El Sistema Dual de Constitucionalidad", en el que se incorporó al Tribunal de Garantías Constitucionales (TGC) (GARCIA BELAUNDE, 1982, pág. 145).

La Constitución de 1993 repite la fórmula de la constitución de 1979, con la única salvedad de que reemplaza al Tribunal de Garantías Constitucionales (TGC) por el Tribunal Constitucional (TC).

El control de justicia constitucional Ilamado "Sistema difuso" o "Judicial Review", como señala el profesor Aníbal Quiroga León, basa su esencia y cualidad en dos aspectos fundamentales que le dan la denominación y principales características funcional y espacial.

a. Funcional, porque se halla sistemáticamente ubicado como atributo constitucional «innominado» de toda constitución escrita.

b. Espacial, porque en su modelo de origen, el único escenario válido en el que el juzgador ordinario abre su facultad constitucional de juzgar la inconstitucionalidad de una ley será su confrontación, en un caso concreto, con los bienes jurídicos tutelados; materia de una real controversia judicial.

El mismo autor agrega, que la característica funcional y espacial, hacen que este sistema de control constitucional sea una justicia constitucional subsidiaria, residual y fundamentalmente subjetiva (QUIROGA LEÓN, 2005). 
Subsidiaria, porque sobreviene (incidental) necesariamente a la labor judicial ordinaria de los Tribunales de Justicia.

Residual o efecto inter partes, porque la actividad de control constitucional que hace el juez ordinario está «añadida» a su tarea principal, donde el control constitucional indirecto y limitado, sólo vincula a las partes en conflicto, a las partes que estuvieron involucradas en el proceso judicial (CASTAÑEDA OTSU, 2004).

Subjetivoo de «justicia subjetiva» porqueesel derecho delos sujetos, su derecho subjetivo concreto, determinado y determinable, el que servirá de base y sustento del examen de constitucionalidad; en otras palabras, el examen de constitucionalidad es de carácter concreto, a partir de un caso (QUIROGA LEÓN, 2005, pág. 230).

\section{El control difuso en sede administrativa}

En principio, es importante tener presente, que la función administrativa, es toda actividad permanente, concreta y práctica del Estado, que tiende a la satisfacción inmediata de las necesidades del grupo social y de los individuos que la integran.

Estas potestades administrativas están adscritas a una función delegada por ley en favor de la Administración; esto quiere decir que la competencia en sede administrativa tiene reserva legal; solo puede originarse en la Constitución y la ley, por tanto, debe ser expresa, excepcionalmente pueden existir potestades discrecionales.

Respecto a la función administrativa el jurista Serra Rojas dice que es la actividad que normalmente corresponde al Poder Ejecutivo, se realiza bajo el orden jurídico y limita sus efectos a los actos jurídicos concretos o particulares, que tiene como finalidad la prestación de un servicio público o la realización de las demás actividades que le corresponden en sus relaciones con otros entes públicos o con los particulares, reguladas por el interés general y bajo un régimen de policía o control (SERRA ROJAS, 1983).

Conforme al ordenamiento jurídico vigente, se reconocen diversas potestades en la Administración Pública moderna, tales como potestades de inspección, sancionadoras, normativas, reglamentarias, certificantes, arbitrales, entre otras (ESTEVE PARDO, 2011).

Para García de Enterría, existen las potestades "innovativas" y "conservativas", clasificación que se organiza en función de la creación, modificación o extinción de situaciones jurídicas o, por el contrario, en la mera validación y vigilancia de situaciones jurídicas ya existentes. Por lo tanto, el jurista referido, cuando aborda las potestades innovativas, hace alusión a las potestades: Reglamentaria, Expropiatoria y de Policía; mientras que, en las conservativas, se refiere a las potestades de Certificación. (GARCÍA DE ENTERRÍA, 1985). 
El maestro Pando Vílchez indica: "(...) la administración se encuentra inexorablemente sujeta al principio de legalidad. Todo lo que haga o decida hacer tiene que tener como fundamento una disposición expresa que le asigne la competencia para poder actuar de tal o cual manera (...) el fundamento de la Administración, en ejercicio de sus funciones, solo puede hacer lo que la ley le permite hacer y está impedido de hacer lo que la ley no le faculta (...) la ley como norma de inferior jerarquía inmediata debe, en aplicación del principio de legalidad, ser acorde con la Constitución y sus principios" (PANDO VILCHEZ, 2006).

ConformealoexpresadoporPandoVílchez,laAdministración Públicanotiene capacidad para declarar inconstitucional una ley, dado que está obligada a ejecutarla y cumplirla, conforme al principio de legalidad; aun cuando la inconstitucionalidad sea manifiesta; la administración pública debe cumplir con esta ley, indica que, de resultar contraria a la Constitución, se proponga su inconstitucionalidad.

No obstante, esta afirmación, el tránsito del Estado de Derecho a un Estado Constitucional de Derecho denota que la Constitución es una norma de jerarquía suprema y de cumplimiento obligatorio; por lo que, conforme a los artículos 38, 51 y 138 de la Carta Política, la Administración Publica está facultada para ejercer control constitucional difuso por cumplir funciones jurisdiccionales.

En efecto, Monroy Gálvez (2009, p.389) explica que el término jurisdicción en general refiere al poder genérico que un órgano del Estado sea Legislativo, Jurisdiccional o Administrativo, ejerce sobre un individuo.

En esa perspectiva, el jurista Rubio Salcedo afirma que: a partir de la aplicación de normas legales, la administración pública podía afectar directamente derechos fundamentales de los administrados, con esta afectación de los derechos fundamentales se trasgrede la Constitución Política. Indica que no existe necesidad de implementar nuevos mecanismos para establecer atribuciones y/o facultades para permitir la inaplicación de las normas legales inconstitucionales, pues el artículo 51 de la Constitución no hace mayor distinción entre personas naturales o jurídicas, personas de Derecho Privado o Derecho Público frente a la aplicación del Principio de supremacía de la Constitución (RUBIO SALCEDO, 2004).

La postura de Rubio Salcedo es bastante clara sobre la inaplicación de las normas legales inconstitucionales en sede administrativa, cuando expresa que: "(...) puede la Administración Pública inaplicar normas inconstitucionales de carácter legal, no significando esto una infracción al principio de legalidad que rige la vida, funcionamiento y orden de la administración, y menos aún, una infracción al ordenamiento jurídico mismo". Igualmente señala que la actuación de la administración será revisable en sede judicial; y será el magistrado finalmente quien podrá decidir si dicha aplicación es adecuada o no"(RUBIO SALCEDO, 2004). EI mismo autor, considera que en la Administración Pública debe existir competencia 
expresa para el ejercicio del control difuso administrativo; sin embargo, podría decirse que la competencia para la aplicación del control difuso administrativo radica en el Art. 51 de la Constitución Política.

En dicho contexto, desde nuestra perspectiva, el artículo 51 de la Carta Política establece el principio de supremacía constitucional, en cuyo principio todo el ordenamiento jurídico y no solo la Administración Pública descansa; en consecuencia, la Constitución faculta implícitamente a la Administración Pública ejercer control difuso constitucional.

Coherente con lo dicho, el maestro Huamán Ordoñez señala "[...] Con la asignación del control difuso en sede administrativa, que no es una potestad ni competencia administrativa, sino un deberconstitucional, se consolida el controldel poder; principalmente atendiendo a que la administración debe proteger los derechos fundamentales de los ciudadanos, teniendo presente que el interés público es la búsqueda y concretización del bienestar social como fin público necesario" (HUAMÁN ORDOÑEZ, 2017).

El mismojurista, indica que resultaría ilógico sostener que la Administración se encamine a aplicar una norma que vulnera la Constitución y que no pueda realizar nada al respecto cuando, pese a tal precisión, proceda de manera contraria, por el deleznable argumento de que no hay disposición jurídica que la habilite a realizar un control de constitucionalidad (HUAMÁN ORDOÑEZ, 2017, pág. 126).

En esa misma línea de pensamiento, el maestro Alfredo Bullard expresa que los derechos fundamentales en sede administrativa son, sin ninguna duda, un límite importante a la aplicación del Principio de Legalidad; agrega que el control difuso debe operar en aquellas circunstancias concretas en que el conflicto entre el principio de legalidad y el de jerarquía de las normas no sea realmente serio. "[...]Estos elementos hacen que el tinte garantista del principio de legalidad no se vea seriamente afectado, y que por el contrario se vea reforzado por el principio de jerarquía, que tutela los derechos fundamentales" (BULLARD GONZÁLEZ, 2007).

Por su parte el jurista Cortez Tataje sobre el tema sostiene: "Contrario a ello, somos testigos de que en muchos países se vienen implementando tribunales administrativos independientes de la estructura judicial, así como se ha extendido el reconocimiento del arbitraje, el fuero militar y otros. En el caso peruano, la Constitución Política en el artículo 138 le otorga carácter jurisdiccional al arbitraje lo cual implica una ruptura de los paradigmas tradicionales al otorgar reconocimiento constitucional a un régimen de solución de controversias de carácter privado, en el que la intervención del Estado es casi nula" (CORTEZ TATAJE, 2014).

Asimismo, refiere "[...] En este contexto, podemos afirmar que dependiendo del paradigma y cultura jurídica que defendamos, será posible encontrar razones para justificar la aplicación del control difuso en sede administrativa. De este modo, bajo el 
paradigma constitucional del deber estatal que exige a la Administración Pública velar que sus competencias y actuaciones sean constitucionales, se pueden encontrar sólidos argumentos para afirmar que el control difuso administrativo es posible en razón de que la observancia del principio de legalidad no resulta suficiente o puede ser sobrepasado cuando el legislador apruebe normas que resulten contrarias a los principios y derechos reconocidos en la Constitución" (CORTEZ TATAJE, 2014, págs. 49-50).

Precisamente, el doctor Martín Tirado refiere que los recursos administrativos están íntimamente relacionados con el control difuso administrativo, pues al efectuar el control de sus propios actos, la Administración (tribunales administrativos u órganos colegiados de competencia nacional) debe verificar la constitucionalidad del acto impugnado por el administrado en primer lugar y luego evaluar su legalidad (MARTIN TIRADO, 2010)

A su turno el maestro Bustamante Alarcón, hace alusión a la potestad hetero compositiva de algunos tribunales administrativos, expresa: "En tanto el ordenamiento jurídico le ha otorgado a la Administración una función cuasi jurisdiccional, implícitamente la propia Constitución le ha otorgado los poderes y los deberes necesarios para que el ejercicio de esa función sea válido. Esto significa que, si en el marco de un procedimiento administrativo se presenta un conflicto entre una norma constitucional y otra de inferior jerarquía, entonces la Administración debe aplicar el artículo 51 de la Constitución y preferir la norma constitucional por encima de la legal, al momento de emitir una decisión."

Agrega dicho autor, que en el mundo actual la Administración ha ganado para si un espacio enorme como órganos de solución y prevención de diversos conflictos intersubjetivos. En dichos casos, la Administración ejerce una actividad cuasi jurisdiccional porque resuelve o previene conflictos o impone sanciones, a través de una decisión vinculante $u$ obligatoria que es impuesta a las partes o administrados en el marco de un procedimiento administrativo (BUSTAMANTE ALARCON, 2002, pág. 38).

De otro lado, el Tribunal Constitucional ha establecido que el principio de legalidad no solo constituye la mera aplicación de las normas con rango legal; sino que la Administración debe analizar su compatibilidad con el orden objetivo de principios y valores constitucionales, aplicando criterios de razonabilidad, racionalidad y proporcionalidad.

En consecuencia, el principio de legalidad administrativa no se opone a la normatividad superior de la Constitución y es lógico que, en un Estado Constitucional de Derecho, la Administración Pública también se encuentra sometida a ella. La Constitución es norma jurídica fundamental. Ello implica que sujeta a sus destinatarios; precisamente uno de esos destinatarios es la propia Administración Publica que, por su carácter de poder público, está vinculada, y más aún si con su actuación puede vulnerar derechos fundamentales de los ciudadanos (administrados). 
En otro extremo, se ha planteado que, ante la dificultad de ejercer control constitucional difuso en sede administrativa, debería contemplarse legislativamente la posibilidad de comunicar a la Defensoría del Pueblo la incompatibilidad de una norma infra constitucional con la Carta Política, para que dicho órgano interponga una acción de inconstitucionalidad; o sea el propio administrado sea quien haga valer un amparo o hábeas corpus si se vulnera un derecho fundamental.

Como es obvio suponer, estos planteamientos no resuelven en lo absoluto la vulneración de derechos fundamentales del administrado, menos la aplicación de una norma inconstitucional, pues si bien la Defensoría del Pueblo ostenta facultades para interponer acciones de inconstitucionalidad esta iniciativa para proteger derechos de una persona es poco probable que sea eficaz y la incoación de posibles acciones de garantía como el amparo o habeas corpus, por el tiempo que dura el procedimiento, que a veces llega en última instancia ante el Tribunal Constitucional, convertirá en injusto e inexistente la protección de derechos fundamentales en sede administrativa; por tanto inexistente la eficacia vertical de la Constitución y la Supremacía Constitucional, de modo no compartimos dicho planteamiento.

Finalmente, no debe perderse de vista, que el derecho no permanece estático, adversamente está en constante cambio; consiguientemente las normas, doctrina y los criterios jurisprudenciales, se modifican, pues deben ser compatibles con la realidad social; máxime si convivimos con la globalización. Y es que precisamente el precedente del Tribunal Constitucional que deja sin efecto el control difuso en sede administrativa constituye un retroceso en la interpretación de la Carta Política y un acto perjudicial a los derechos fundamentales de los administrados; toda vez que el hecho de transitar por la vía judicial y recién cuestionar la inconstitucionalidad de una norma legal, resulta a todas luces injusta, onerosa y perniciosa a los derechos fundamentales del administrado.

Por lo tanto, resulta inconstitucional por inconsistente la decisión del Tribunal Constitucional que deja sin efecto el precedente vinculante que autorizaba control constitucional en sede administrativa; además el incumplimiento de los criterios establecidos por el propio colegiado para apartarse de un precedente vinculante, vulnerando con ello el derecho fundamental de motivación de resoluciones. Lo más grave es haber dejado sin efecto dicho precedente en una controversia absolutamente ajena a la aplicación de control difuso en sede administrativa; incurriendo en una decisión ilógica e incongruente, pues extrañamente se indica que dicha decisión no significa inobservar reglas y principios constitucionales, señalando que la Administración Pública está sometida a la Constitución; es decir la obligación de respetar los derechos fundamentales y garantías procesales, como es el debido proceso, derecho de defensa y principios constitucionales, legalidad, razonabilidad, proporcionalidad, interdicción de la arbitrariedad. Por tanto, con esta decisión contradictoria, se coloca a la Administración Publica en una incertidumbre innecesaria. 


\section{Crítica a la jurisprudencia del Tribunal Constitucional, discusión de resultados}

1) Con el precedente vinculante establecido en la sentencia emitida en el expediente 3741-2004-PA/TC, los órganos colegiados de competencia nacional tenían facultades para inaplicar una ley, cuando de su análisis e interpretación resultaba contraria a la Constitución; sin embargo, se niega dicho control en la sentencia emitida en el expediente 04293-2012-PA/TC. (Caso Consorcio Requena).

Se hace notar que el control difuso constitucional en sede administrativa cumple una función de capital importancia en la protección y preservación de derechos fundamentales; además significa un límite importante frente a decisiones arbitrarias, de autoridades y funcionarios; sin dejar de mencionar que dicha facultad de control, pone de manifiesto la supremacía constitucional, propia de un Estado Constitucional de Derecho. Lo contrario, induce a la Administración pública a la solución de casos, aplicando normas legales con manifiesta inconstitucionalidad, so pretexto del principio de legalidad, en perjuicio de los administrados, quienes, para proteger sus derechos, tendrán que acudir a la vía judicial, con pérdida de tiempo y dinero.

En efecto, el Tribunal Constitucional ha señalado, que el precedente constitucional vinculante es aquella regla jurídica expuesta en un caso particular y concreto que el Tribunal decide establecer como regla general; y que, por ende, deviene en parámetro normativo para la resolución de futuros procesos de naturaleza homóloga.

Siendo así, el Tribunal Constitucional habría obrado, acorde con el artículo VII del Título Preliminar del Código Procesal Constitucional, el cual preceptúa que "(...) las sentencias del Tribunal Constitucional que adquieren autoridad de cosa juzgada constituyen precedente vinculante cuando así lo exprese la sentencia, precisando el extremo de su efecto normativo. Cuando el Tribunal Constitucional resuelva apartándose del precedente, debe expresar los fundamentos de hecho y de derecho que sustentan la sentencia y las razones por las cuales se aparta del precedente".

En ese contexto, desde nuestro análisis y acorde a la doctrina y jurisprudencia desarrollada, sin ninguna duda dicho colegiado se habría abstraído de los elementos indispensables para distanciarse de un precedente vinculante, que en la práctica sostenía la plena vigencia de derechos fundamentales en sede administrativa; siendo a todas luces un lamentable retroceso en la interpretación de los artículos 38, 51 y 138 de la Carta Política, propiciando desprotección de derechos fundamentales.

En ese sentido, el apartamiento o sustitución de un precedente vinculante está sujeto a los elementos siguientes: 
a) Expresión de los fundamentos de hecho y derecho que sustentan dicha decisión.

b) Expresión de la razón declarativa-teológica, razón suficiente e invocación preceptiva en que se sustenta dicha decisión.

c) Determinación de sus efectos en el tiempo.

Del análisis del precedente en referencia, salta a la vista, que no se ha expuesto claramente los fundamentos de hecho, que exige el apartamiento de un precedente constitucional, tal es así que no se ha hecho mención alguna a los casos en que la administración pública habría aplicado erróneamente el control difuso constitucional; tampoco se ha hecho mención a los supuestos perjuicios que estaría originando el control difuso en sede administrativa al no tener un mecanismo de consulta, como lo tiene el Poder Judicial o la forma como estaría afectando al control constitucional dual, menos se ha referido a los efectos que habría producido dicho control durante su vigencia y cuáles serían las implicancias del retiro de dicha facultad para los administrados, respecto a los derechos fundamentales en un Estado Constitucional de derecho.

Con relación a la razón declarativa-teológica, el mismo colegiado ha expresado (expediente 0024-2003-AI/TC) que es la regla o principio que el Colegiado establece y precisa como indispensable $y$, por ende, como justificante para resolver la litis; señala que es aquella parte de la sentencia constitucional que ofrece reflexiones referidas a los valores y principios políticos contenidos en las normas declarativas y teleológicas insertas en la Constitución; se trata de un conjunto de juicios de valor concomitantes a la interpretación y aplicación de las normas técnicas y prescriptivas de la Constitución, que permiten justificar una determinada opción excogitada por el Colegiado, para consolidar la ideología, la doctrina y hasta el programa político establecido.

En el caso del precedente contenido en el expediente 04293-2012-PA/TC. (Caso Consorcio Requena), como es evidente, es absolutamente inexistente la razón declarativa-teleológica, vinculada al control difuso constitucional en sede administrativa, pues a partir del fundamento 30, se desarrollan argumentos aislados al problema de fondo y se limita hacer una crítica aislada al expediente Salazar Yarlenque. Tal situación anormal pone en evidencia el incumplimiento, de las condiciones para el uso del precedente constitucional vinculante, pues precisamente dicha argumentación no ha sido una herramienta técnica que facilite la ordenación y coherencia de la jurisprudencia, no ha sido necesaria para la solución del caso planteado; habiendo el Tribunal Constitucional sentado un pésimo precedente al pronunciarse de modo subrepticio y soterrado a sabiendas que el caso resuelto no tiene relación con la materia controvertida, no existe ninguna conexión fáctica ni jurídica entre el caso analizado y el desarrollo del precedente que deja sin efecto el control difuso en sede administrativa, atentando 
de este modo abiertamente las garantías de la debida motivación, congruencia y la adecuada argumentación jurídica, que el Tribunal está obligado a observar.

En lo pertinente a la determinación de los efectos en el tiempo, tampoco se ha previsto acción alguna. Y es que el Tribunal Constitucional está facultado para emitir sentencias con efecto diferido, o aplicación inmediata de sus efectos, y no se ha tenido en cuenta los efectos indirectos que dicha sentencia produce para la ciudadanía en su conjunto y la Administración Pública. Tal vez, hubiera sido recomendable que la aplicación del precedente vinculante opere con efecto diferido (vacatio sententiae), en salvaguarda de la seguridad jurídica, principalmente por el cambio súbito del precedente, que inevitablemente será causa de situaciones conflictivas innecesarias.

2) Por otra parte, el Tribunal Constitucional, afirma que, en la emisión del precedente vinculante sobre control difuso en sede administrativa, se habrían incumplido reglas establecidas en las sentencias emitidas en los expedientes 00024-2003Al/TC, y 3741-2004-PA/TC; es decir los siguientes presupuestos básicos:

a) Evidencia sobre operadores jurisdiccionales o administrativos, que vienen resolviendo con distintas concepciones o interpretaciones sobre una determinada figura jurídica; es decir, cuando se acredita la existencia de precedentes conflictivos o contradictorios.

b) Evidencia de los operadores jurisdiccionales o administrativos que vienen resolviendo en base a una interpretación errónea de una norma del bloque de constitucionalidad; lo que genera una indebida aplicación de la misma.

c) Evidencia de la existencia de un vacío normativo.

d) Evidencia de la existencia de una norma carente de interpretación jurisdiccional en sentido lato aplicable a un caso concreto, y en donde caben varias posibilidades interpretativas.

e) Evidencia de la necesidad de cambiar o revocar el precedente vinculante.

f) Cuando en el marco de un proceso constitucional de tutela de derechos, el Tribunal constata la inconstitucionalidad manifiesta de una disposición normativa, que no solo afecta al reclamante, sino que tiene efectos generales que suponen una amenaza latente para los derechos fundamentales. En este supuesto, al momento de establecer el precedente vinculante, el Tribunal puede proscribir la aplicación a futuros supuestos, del total o parte de la disposición o de determinados sentidos interpretativos o puede también establecer sentidos interpretativos que son compatibles con la Constitución.

Respecto a ello, nos permitimos sostener, que no es cierto dicho incumplimiento; por lo siguiente:

a) Es falso, que en la praxis administrativa no existan, vacíos normativos o interpretaciones contradictorias principalmente respecto de los artículos 38, 
51 y 138 de la Constitución Política, pues se ha referido que la Carta Política por su naturaleza de fundamental, contiene normas abiertas y generales, dado que está conformada por principios y valores; de modo que no es cierto que en sede administrativa exista uniformidad en la interpretación de dichos artículos, máxime cuando dichos artículos constitucionales están referidos a la supremacía constitucional, jerarquía normativa y facultades para el control difuso constitucional.

b) No debe perderse de vista, que la Constitución no solo es ese vértice superior del ordenamiento jurídico, sino que además de norma jurídica es, y por, sobre todo, norma política continente de principios y postulados fundamentales para la organización política, social y económica de la Nación, los que por su propia naturaleza y finalidad han de tener una vigencia históricamente dinámica, cambiante con el desarrollo del país.

c) Es importante resaltar, que el mismo Colegiado, en el expediente 37412004-AA/TC, en el fundamento 6, hace una interpretación del artículo 51, cuando señala (...) el deber de respetar y preferir el principio jurídico de supremacía de la Constitución también alcanza, como es evidente, a la administración pública. (...) Al igual que los poderes del Estado y los órganos constitucionales, se encuentra sometida, en primer lugar, a la Constitución de manera directa $y$, en segundo lugar, al principio de legalidad, de conformidad con el artículo $51^{\circ}$ de la Constitución. En este caso se hace una interpretación constitucional, precisamente porque en sede administrativa se presentan interpretaciones contradictorias.

d) Igual situación ocurre con el artículo 138 de la Carta Política, cuando señala (...) De acuerdo con estos presupuestos, el Tribunal Constitucional estima que la administración pública, a través de sus tribunales administrativos o de sus órganos colegiados, no sólo tiene la facultad de hacer cumplir la Constitución, dada su fuerza normativa, sino también el deber constitucional de realizar el control difuso de las normas que sustentan los actos administrativos y que son contrarias a la Constitución o a la interpretación que de ella haya realizado el Tribunal Constitucional (artículo VI del Título Preliminar del Código Procesal Constitucional). Ello se sustenta, en primer lugar, en que si bien la Constitución, de conformidad con el párrafo segundo del artículo $138^{\circ}$, reconoce a los jueces la potestad para realizar el control difuso, de ahí no se deriva que dicha potestad les corresponda únicamente a los jueces, ni tampoco que el control difuso se realice únicamente dentro del marco de un proceso.

e) Con lo establecido por el Supremo Interprete, es claro, que se ha despejado necesariamente interpretaciones erróneas respecto de los artículos 51 y 138 de la Constitución, deslizadas principalmente en la Administración Pública.

3) Asimismo, el Tribunal Constitucional, al dejar sin efecto el precedente vinculante sobre control difuso en sede administrativa, establece una nueva posición, 
respecto a la interpretación del artículo $138^{\circ}$ de la Constitución Política pues, distinto a lo expresado en el expediente 3741-2004-AA/TC, concluye afirmando que el control difuso constitucional es competencia exclusiva y excluyente de los órganos judiciales. Señala enfáticamente, que dicha atribución corresponde solo a los que ejercen función jurisdiccional por mandato constitucional y no para Tribunales Administrativos.

Sobre el particular, es preciso señalar, que la interpretación de las disposiciones constitucionales corresponde a un método especial, pues las modernas corrientes sobre interpretación constitucional han cambiado. $Y$ es que los tradicionales conceptos inicialmente sistematizados por Savigny han sido superados y ya no se considera a la Constitución sólo como ese vértice superior del ordenamiento jurídico, sino que además de norma jurídica es, y por, sobre todo, norma política de principios y postulados fundamentales para la organización política, jurídica, social y económica de la Nación. Entonces los esquemas de interpretación que aporta la dogmática jurídica tradicional resultan limitados.

En esa perspectiva la interpretación sistemática supone, que la Constitución es un sistema normativo, que comprende un conjunto de partes que se interrelacionan según ciertos principios, de manera que siempre se puede encontrar respuesta a las necesidades normativas para la vida social, integrando las partes y aplicando los principios. Las normas regla se interrelacionan mediante las normas principio, de manera que al final toda la Constitución tiene una armonía interna que permite solucionar los problemas de interpretación y aplicación del Derecho Constitucional.

En consecuencia, la interpretación sistemática trata de mirar íntegramente la constitución y dar repuestas normativas constitucionales, no desde un texto normativo especifico sino desde el conjunto de reglas y principios constitucionales.

Por otro lado, la teleología se define como la teoría de las causas finales, de los fines últimos a los cuales está destinada determinada institución, en nuestro caso la Constitución Política del Estado. En consecuencia, la interpretación teleológica tiene especial importancia en el derecho constitucional, pues este tiene por finalidad organizar en sus más amplios espacios a la sociedad integralmente considerada y, por ello mismo, establece finalidades tanto de contenido como de forma.

El propio Tribunal ha señalado, que la vigencia de los Derechos Humanos o constitucionales debe ser asumida por el Estado como una responsabilidad teleológica, es decir, como perteneciente a sus propios fines esenciales.

Respecto a la afirmación que el control difuso constitucional es competencia exclusiva y excluyente de los órganos judiciales, el destacado jurista argentino Rafael Bielsa, en su tratado de Derecho Administrativo, manifiesta, que sí se puede hablar de una jurisdicción administrativa; los tribunales administrativos, 
por definición, no forman parte del Poder Judicial, sino del Poder Administrador, de ahí que se hable propiamente de una jurisdicción administrativa.

También el jurista Monroy Gálvez, señala que la función jurisdiccional, es el poder-deber del Estado, previsto para solucionar conflictos de intereses intersubjetivos, controlar las conductas antisociales (faltas o delitos) y también la constitucionalidad normativa, en forma exclusiva y definitiva, a través de órganos especializados que aplican el derecho que corresponde al caso concreto, utilizando su imperio para que sus decisiones se cumplan de manera ineludible, y promoviendo a través de ellas una sociedad con paz social en justicia.

En lo pertinente a la Administración Pública, conforme lo establece el artículo III del Título Preliminar de la Ley 27444, la actuación de la administración pública sirve a la protección del interés general, garantizando los derechos e intereses de los administrados y con sujeción al ordenamiento constitucional y jurídico en general.

De dicha disposición legal saltan a la vista las facultades de la Administración Pública para dirimir conflictos que se presenta entre particulares y el Estado; asimismo controversias intersubjetivas, como ocurre en el procedimiento administrativo trilateral sus decisiones gozan de carácter ejecutorío, es decir son de cumplimiento imperativo e inmediato, produciendo actos administrativos con carácter de cosa decidida y, si no son impugnados en sede administrativa o judicial, son actos firmes e intangibles.

Por lo expresado, consideramos absolutamente constitucional, que el Tribunal u Órgano Colegiado administrativo, al constatar una norma evidentemente inconstitucional, pueda salir con éxito de dicha colisión prefiriendo, entre dos interpretaciones posibles, aquella que se vincula con la Constitución, aplicando el principio de conservación de normas según el cual el intérprete debe preferir, de dos posibles interpretaciones, aquella que conduce a la eficacia y validez de la norma, esto implica que a la Administración Pública no se le puede negar su facultad interpretativa conforme a la Carta Política.

Siendo ello así, consideramos que el Tribunal Constitucional recurre solamente a una interpretación restrictiva y literal del artículo 138, por ello concluye señalando que el control difuso constitucional es competencia exclusiva y excluyente de los órganos judiciales, olvidando que la Carta Política requiere de una interpretación especial, pues no solo contiene normas sino fundamentalmente valores y principios que exigen de la teleología y criterio de interpretación sistemática. Por lo tanto, el deber de respetar y preferir el principio jurídico de supremacía de la Constitución también alcanza a la Administración Pública. Y es que de conformidad a lo prescrito por los artículos 38, 51 y 138 de la Carta Política, la Administración Pública está, al igual que los poderes del Estado y los órganos constitucionales, sometida, en primer lugar, a la Constitución de manera directa y, en segundo lugar, al principio de legalidad. Esta vinculación de la administración pública a la Constitución se expresa sin ninguna duda en el artículo IV del Título Preliminar de la Ley del Procedimiento 
Administrativo General, referido al principio de legalidad; el mismo enarbola la supremacía jurídica de la Constitución.

4) En otra parte, el Tribunal Constitucional señala que en el control difuso judicial se ha establecido un mecanismo de control (elevar en consulta a la Sala Constitucional y Social de la Corte Suprema), lo que no ocurre en el caso de los tribunales administrativos.

Al respecto, el Artículo 14 de la Ley Orgánica del Poder Judicial indica: "cuando los magistrados al momento de fallar el fondo de la cuestión de su competencia, en cualquier clase de proceso o especialidad, encuentren que hay incompatibilidad en su interpretación, de una disposición constitucional y una con rango de ley, resuelven la causa con arreglo a la primera. Las sentencias así expedidas son elevadas en consulta a la Sala Constitucional y Social de la Corte Suprema, si no fueran impugnadas. Lo son igualmente las sentencias en segunda instancia en las que se aplique este mismo precepto, aun cuando contra éstas no quepa recurso de casación."

En todos estos casos los magistrados se limitan a declarar la inaplicación de la norma legal por incompatibilidad constitucional, para el caso concreto, sin afectar su vigencia, la que es controlada en la forma y modo que la Constitución establece.

De lo descrito en la norma legal mencionada, se infiere claramente, que dicha consulta, no constituye recurso impugnativo; se trata de un mecanismo judicial para un reexamen por parte del superior de lo ya resuelto, a fin de tener certeza si el derecho fue debidamente interpretado.

Al respecto el maestro Véscovi, indica que dicha consulta es un privilegio injustificado y demora inútil, pues del procedimiento se verifica, que sirve para generar uniformidad y predictibilidad. (VÉSCOVI, 2011)

Siendo así, consideramos que la ausencia de un mecanismo de control en sede administrativa no descalifica una función de control difuso en sede administrativa, en tanto estas decisiones pueden ser objeto de cuestionamiento en la vía judicial; toda vez que la facultad de impugnar las decisiones de los tribunales administrativos está siempre abierta, de acuerdo con el artículo $148^{\circ}$ de la Constitución. Entonces será revisable en sede judicial; y será el magistrado finalmente quien podrá decidir si dicha aplicación es adecuada o no. Igualmente, es importante ponderar el hecho de considerar los procedimientos administrativos que se siguen en dichas entidades, como procedimientos garantistas y de protección del debido proceso; toda vez que, como en cualquier proceso judicial, rigen principios que salvaguardan el «debido procedimiento» que garantiza los derechos del administrado, estando proscrita cualquier actuación arbitraria.

Por otro lado, es importante hacer notar, que este mecanismo de consulta no está previsto para el ejercicio del control difuso de constitucionalidad en la jurisdicción arbitral, tampoco para el caso del Jurado Nacional de Elecciones y la 
jurisdicción militar pues, conforme a sus propios ordenamientos, si se violentan derechos fundamentales siempre serán objeto de control jurisdiccional. No obstante, se mantiene sus facultades de control difuso constitucional.

5) En otro extremo, el Tribunal Constitucional, ha señalado que el control constitucional difuso en sede administrativa afecta el sistema de control dual de jurisdicción constitucional.

Este sistema de control difuso es paralelo al Control Concentrado, dando lugar a un sistema de control constitucional dual. Este sistema dual ha sido adoptado en numerosos países de América Latina, bajo la influencia europea, particularmente en Colombia, Guatemala, Bolivia, Perú y Ecuador.

Sin embargo, la afirmación del Tribunal Constitucional. en esta parte, carece de una elemental motivación y argumentación que sostenga dicho cuestionamiento; es inexistente dicha motivación o en todo caso se incurre en una aparente motivación; por tanto, se viola el derecho a una decisión debidamente motivada. El Tribunal Constitucional no ha sustentado cómo y porqué se afecta dicho sistema y qué perjuicios se estarían produciendo con dicha afectación; su decisión se ha limitado únicamente a señalarlo, sin esgrimir razón ni justificación alguna; por lo tanto, en dicha decisión es ausente la motivación interna y externa, resultando injusta e irrazonable. El incumplimiento del deber de motivación hace tangible la falta de consistencia y firmeza de nuestro supremo interprete constitucional, pues pareciera una buena intención, más que una decisión debidamente meditada.

6) Otro de los argumentos aparentemente desarrollados por el Tribunal Constitucional, ha sido la escasa aplicación de dicha atribución en dicha sede.

Al respecto, efectivamente de la evaluación efectuada en las resoluciones emitidas por los Tribunales Administrativos (Tribunal Indecopi, Tribunal Registral, Tribunal Fiscal y Tribunal Servir), se verifica una escasa aplicación de esta potestad de control constitucional; sin embargo tal situación escasa no justifica, de ningún modo, que dicha herramienta fundamental en la protección de derechos fundamentales en sede administrativa quede sin efecto, pues en lugar de modernizar a la Administración Pública con capacidades de interpretación constitucional, además de comprometer a autoridades y funcionarios en la protección y resguardo de derechos fundamentales, se incurre en un abierto retroceso, en el desarrollo de jurisprudencia y precedentes vinculantes del Tribunal Constitucional. Y es que esta decisión condena a la Administración Pública a un papel robótico y mecánico en la toma de sus decisiones y al administrado a transitar por la vía judicial para que, con pérdida de tiempo, dinero y esfuerzo, pueda lograr el reconocimiento de su derecho.

Este razonamiento es ilógico e irreal, pues bajo este argumento, diversas leyes actualmente vigentes, por falta de aplicación tendrían que derogarse. Estimamos que el Colegiado, no ha tenido en cuenta que una facultad administrativa de esa naturaleza solo ha tenido el propósito de garantizar los 
derechos fundamentales de los administrados, frente a decisiones arbitrarias que se dan en la Administración Pública.

7) También, dicho Colegiado ha referido que el control constitucional difuso en sede administrativa afecta el principio de división de poderes, al permitir que el Poder Ejecutivo controle las normas del Poder Legislativo.

Sobre el particular, es importante tener presente que el principio de separación de poderes, previsto en el artículo 43 de la Carta Política vigente, implica, que la actual estructura del Estado descansa en los clásicos tres (3) poderes, asumiendo cada poder competencias distintas y excluyentes, con la finalidad principal de hacer efectivo un control y fiscalización reciproco entre el Poder Ejecutivo, Poder Legislativo y el Poder Judicial.

Por otro lado, también resulta relevante tener presente que, como consecuencia de la vigencia de un Estado de Derecho, esta división de poderes responde inevitablemente al principio de legalidad como una garantía y limitación frente a posibles actuaciones arbitrarias en contra de los particulares, o la posibilidad de una injerencia en las atribuciones de otros Poderes; con ello aparecen las competencias exclusivas y excluyentes, conforme al ordenamiento legal.

Por lo tanto, al Poder Judicial, le corresponde la función de administrar justicia, que es la facultad que tiene para resolver conflictos de interés, mediante la mera aplicación de la ley.

Asimismo, el Estado de Derecho reconoce la independencia de funciones en cada poder del Estado; sin embargo la función jurisdiccional, entendida como la facultad de resolver conflictos de intereses, con autoridad de cosa juzgada, no es exclusiva y excluyente del poder judicial, pues la propia Constitución ha establecido excepciones, como ocurre con la jurisdicción militar, arbitral, Jurado Nacional de Elecciones y otros entes públicos; empero en todo momento se respeta la independencia judicial, siendo vigente el monopolio de la administración de justicia, pues la Administración Pública siempre será objeto de control jurisdiccional, por mandato constitucional.

Sin embargo, la evolución del principio de separación de poderes, y el tránsito a un Estado Constitucional de derecho, denota que la protección de los derechos e intereses de los particulares no solo es a partir de la mera aplicación de la ley, tampoco únicamente bajo la actuación del Poder Judicial, conforme a la concepción clásica de la división de poderes; sino, la protección de derechos fundamentales, sin menoscabar la separación de poderes, se da también en sede administrativa. Tal situación real y concreta de ningún modo comporta la vulneración de la independencia del poder judicial o del Legislativo que, en puridad, protege el principio de división de poderes; consiguientemente es legítimo que un tribunal administrativo que forma parte del Poder Ejecutivo controle las normas dictadas por el Poder Legislativo, en aplicación del principio de supremacía constitucional y la función de control reciproco entre 
poderes, que significa la aplicación de pesos y contrapesos; por ello la Carta Magna, establece la facultad de fiscalización que tiene el Congreso, frente a las acciones que realiza el Ejecutivo y recíprocamente este con relación al Congreso, sin que ello entrañe violación del citado principio de separación de poderes.

Debe recordarse a John Locke y Montesquieu, quienes originalmente postularon al principio de división de poderes, en la necesidad de que existan contrapesos y equilibrios, un balance entre los distintos poderes de un estado para que, a través de los controles entre unos y otros, se garantice la vida, la libertad, igualdad y la propiedad de los ciudadanos, mediante la distribución de responsabilidades y controles entre los distintos poderes, siendo por tanto uno de los pilares fundamentales del Estado de Derecho.

En ese sentido, el fin de la separación de poderes en Montesquieu, no necesariamente ha sido para garantizar que cada poder ejerza únicamente la función que le corresponda, sino combatir los gobiernos despóticos, frente a la posibilidad de injerencia en las decisiones adoptadas, buscando precisamente la independencia en el ejercicio de funciones, para posteriormente consolidar el imperio de la ley (KELSEN H. , La garantía jurisdiccional de la Constitución, 2001).

Entonces, desde un inicio aparece relevante la independencia en el cumplimiento de funciones, para garantizar se respete el imperio de la ley y se vele porque los mandatos normativos se cumplan por todos; ciudadanos, poderes y órganos del Estado. Así, en un Estado de Derecho, no es posible admitir que el poder ejecutivo, pueda impartir órdenes a un juez, respecto a la solución de un determinado caso, menos cuando en dicha causa figuran como parte órganos del gobierno o la administración del Estado.

No debe olvidarse, que, en la realidad actual, se observa que los poderes tradicionales comparten funciones, en tanto que el poder legislativo y ejecutivo, en calidad de poderes políticos, ostentan facultades de resolver conflictos de relevancia jurídica, con efectos de cosa juzgada, siempre y cuando no se recurra al contencioso administrativo, respetando por su puesto la independencia de las funciones asignadas por la Carta Política. Por lo tanto, debe comprenderse adecuadamente la doctrina de la separación de poderes. Entonces la facultad de control difuso constitucional en sede administrativa no vulnera en absoluto dicho principio, dado que será siempre el Poder Judicial que en definitiva determine que la actuación en sede administrativa es legal o no.

\section{Conclusiones}

1) La sentencia del Tribunal Constitucional, que deja sin efecto el control constitucional difuso en sede administrativa; debilita ostensiblemente la protección de derechos fundamentales de los administrados.

2) La decisión, que deja sin efecto el control constitucional difuso en sede administrativa; si bien ya no faculta dicha atribución a los Tribunales 
Administrativos y Órganos Colegiados; sin embargo, por imperio constitucional y el principio de supremacía constitucional, incluso el propio principio de legalidad, estas dependencias administrativas, decidirán siempre prefiriendo las disposiciones constitucionales.

3) Los Tribunales Administrativos y Órganos Colegiados, desde la vigencia del precedente, han aplicado escasamente dicha potestad de control constitucional; sin embargo, la vigencia en el tiempo de dicha atribución de control ha resguardado eficazmente derechos fundamentales de los administrados.

4) Desde una interpretación literal de la Constitución Política del Perú, la función jurisdiccional es atribución exclusiva del Poder Judicial y de otras instancias que por mandato constitucional ejercen función jurisdiccional; empero acorde a una interpretación, extensiva, sistemática y teleológica; la administración Pública, también ejerce función jurisdiccional.

5) La interpretación sistemática y teleológica de los artículos 38, 51 y 138 de la Constitución, faculta a la Administración Pública ejercer control difuso constitucional.

6) El Tribunal Constitucional al dejar sin efecto el precedente vinculante sobre control difuso en sede administrativa, no ha motivado conforme a las reglas impuestas por dicho colegiado para los casos de dejar sin efecto precedentes vinculantes; además ha vulnerado el principio de congruencia al emitir una decisión tan importante, en materias desvinculadas a la aplicación de control difuso.

7) En sede Administrativa no está previsto un mecanismo de consulta; sin embargo, debe recordarse, que las decisiones de la Administración Pública pueden ser sometidas por el administrado ante la autoridad jurisdiccional, instancia que finalmente ratifica la actuación del Colegiado administrativo.

\section{Referencias y bibliografía}

BREWER-CARIAS, A. (2005). Los Principios fundamentales del derecho público (Con una Introducción General sobre los Principios del Derecho Administrativo en la Ley General de la Administración Pública de Costa Rica. San José, Costa Rica: Investigaciones Jurídicas.

BULLARD GONZÁLEZ, A. (2007). Verdades y falacias sobre el control difuso de las normas por las autoridades administrativas a la luz de los nuevos pronunciamientos del Tribunal Constitucional. Lima: Palestra.

BUSTAMANTE ALARCON, R. (2002). Control Difuso y Administración. ¿Es viable que la Administración ejerza control difuso de la Constitucionalidad Normativa? Revista Jurídica del Perú, 45 
CASTAÑEDA OTSU, S. Y. (2004). Derecho Procesal Constitucional (Segunda ed.). Lima: JURISTA EDITORES E.I.R.L.

CORTEZ TATAJE, J. C. (mayo de 2014). ¿Es posible aplicar el control difuso en sede administrativa? Actualidad Jurídica, 49-50.

ESTEVE PARDO, J. (2011). Lecciones de Derecho Administrativo. Barcelona; Madrid; Buenos Aires: Marcial Pons.

FERNÁNDEZ SEGADO, F. (1994). El nuevo Ordenamiento Constitucional del Perú: Aproximación a la Constitución de 1993. Lecturas sobre temas Constitucionales (10), 301.

GARCIA BELAUNDE, D. (1982). Constitución y Política (Segunda ed.). Lima: Biblioteca Peruana de Derecho Constitucional.

GARCÍA DE ENTERRÍA, E. (1985). La Constitución como Norma y el Tribunal Constitucional. Madrid: Civitas.

HIGTHON DE NOLASCO, E. I. (2003). Justicia en cambio: un nuevo proyecto para la Administración de Justicia. Buenos Aires: Rubinzal-Culzoni.

HUAMÁN ORDOÑEZ, L. A. (2017). Procedimiento Administrativo General Comentado. Lima: Jurista editores.

MARTIN TIRADO, R. (2010). Los Recursos Administrativos y el Control Difuso en la Administración Pública. Revista de Derecho Administrativo (9), 231

PANDO VILCHEZ, J. (2006). La administración frente a la norma inconstitucional: ¿Control de constitucionalidad y control de legalidad Administrativa? (C. d. República, Editor) Obtenido de http://www.congreso.gob.pe/juridica/ documentos/ctrl_legal_administrativo.pdf

QUIROGA LEÓN, A. (2005). Derecho Procesal Constitucional y el Código Procesal Constitucional. Lima: ARA Editores E.I.R.L.

RUBIO SALCEDO, C. (2004). El principio de legalidad y la inaplicación de normas legales inconstitucionales por la Administración Publica en el ordenamiento peruano actual. Revista Jurídica del Perú.

SERRA ROJAS, A. (1983). De o. México: PORRÚA. recho Administrativ

SENTENCIA DEL TRIBUNAL CONSTITUCIONAL, EXP. Nº 0273-93-AA/TC (TRIBUNAL CONSTITUCIONAL 1998 de Enero de 1998).

SENTENCIA DEL TRIBUNAL CONSTITUCIONAL, EXP. Nº008-2003-AI/TC (TRIBUNAL CONSTITUCIONAL 11 de Noviembre de 2003). 
SENTENCIA DEL TRIBUNAL CONSTITUCIONAL, EXP. N 0008-2003-AI/TC (TRIBUNAL CONSTITUCIONAL 11 de Noviembre de 2003).

SENTENCIA DEL TRIBUNAL CONSTITUCIONAL, EXP. Nº008-2003-AI-TC (TRIBUNAL CONSTITUCIONAL 11 de Noviembre de 2003).

SENTENCIA DEL TRIBUNAL CONSTITUCIONAL, EXP. N 0017-2003-AI/TC (TRIBUNAL CONSTITUCIONAL 16 de Marzo de 2004).

SENTENCIA DEL TRIBUNAL CONSTITUCIONAL, EXP. Nº 004-2004-AA/TC (TRIBUNAL CONSTITUCIONAL 13 de Mayo de 2004).

SENTENCIA DEL TRIBUNAL CONSTITUCIONAL, EXP. N² 2192-2004-AA/TC (TRIBUNAL CONSTITUCIONAL 11 de Octubre de 2004).

SENTENCIA DEL TRIBUNAL CONSTITUCIONAL, EXPEDIENTE N 3330-2004-AA/TC (TRIBUNAL CONSTITUCIONAL 11 de Julio de 2005).

SENTENCIA DEL TRIBUNAL CONSTITUCIONAL, EXPEDIENTE N³330-2004-AA/TC (TRIBUNAL CONSTITUCIONAL 2011 de Julio de 2005).

SENTENCIA DEL TRIBUNAL CONSTITUCIONAL, EXP. N 3179-2004-AA/TC (TRIBUNAL CONSTITUCIONAL 18 de Febrero de 2005).

SENTENCIA DEL TRIBUNAL CONSTITUCIONAL, EXP. N 3179-2004-AA/TC (TRIBUNAL CONSTITUCIONAL 18 de Febrero de 2005).

SENTENCIA DEL TRIBUNAL CONSTITUCIONAL, EXP. N 3741-2004-PA/TC (TRIBUNAL CONSTITUCIONAL 14 de Noviembre de 2005).

SENTENCIA DEL TRIBUNAL CONSTITUCIONAL, EXP. N 8495-2006-PA/TC (TRIBUNAL CONSTITUCIONAL 2008). 